\title{
Concentrations of plasma melatonin and luteinizing hormone in domestic gilts reared under artificial long or short days
}

\author{
A. M. Paterson ${ }^{1}$, G. B. Martin ${ }^{2,3}$, A. Foldes ${ }^{4}$, C. A. Maxwell ${ }^{4}$ and \\ G. P. Pearce ${ }^{5}$
}

${ }^{1}$ Animal Production Division, Department of Agriculture, Baron-Hay Court, South Perth, WA 6151, Australia; ${ }^{2}$ School of Agriculture (Animal Science), The University of Western Australia, Nedlands, WA 6009, Australia; ${ }^{3}$ CSIRO Division of Animal Production, Private Bag, Wembley, WA 6014, Australia; ${ }^{4}$ CSIRO Division of Animal Production, PO Box 239, Blacktown, NSW 2148, Australia; and ${ }^{5}$ School of Agriculture (Animal Science), The University of Western Australia, Nedlands, WA 6009, Australia

Summary. Plasma melatonin concentrations were measured every $1-2 \mathrm{~h}$ over $24 \mathrm{~h}$ and plasma luteinizing hormone ( $\mathrm{LH}$ ) concentrations every 15 min over $12 \mathrm{~h}$ in domestic gilts reared under artificial light regimens that had previously been used to demonstrate photoperiodic effects on puberty. In Expt 1, the light regimens both commenced at $12 \mathrm{~h}$ light:12 h dark (12L:12D) and either increased (long-day) or decreased (short-day) by $15 \mathrm{~min} /$ week until the long-day gilts were receiving $16 \mathrm{~L}: 8 \mathrm{D}$ and the short-day gilts 8L:16D at sampling. In Expt 2, both light regimens commenced at 12L:12D and either increased (long-day) or decreased (short-day) by 10 or $15 \mathrm{~min} /$ week to a maximum of 14.5L:9.5D or a minimum of $9 \cdot 5 \mathrm{~L}: 14 \cdot 5 \mathrm{D}$ before being reversed. Sampling took place when daylength had returned to 14L:10D (long-day) or 10L:14D (short-day). In immature gilts housed at 12L:12D (Expt 1) and in postpubertal (Expt 1) and prepubertal (Expt 2) gilts reared under long-day or short-day light regimens, mean plasma melatonin concentrations were basal $(3.6 \mathrm{pg} / \mathrm{ml})$ when the lights were on and increased to peak concentrations $>15 \mathrm{pg} / \mathrm{ml}$ within $1-2 \mathrm{~h}$ after dark, before declining gradually to basal concentrations at or near the end of the dark phase. In prepubertal gilts bearing subcutaneous melatonin implants and reared under long-days (Expt 2), mean plasma melatonin concentration in the $6 \mathrm{~h}$ before dark was $91.9 \pm 5.26 \mathrm{pg} / \mathrm{ml}$ and $125.0 \pm$ $6.66 \mathrm{pg} / \mathrm{ml} 1 \mathrm{~h}$ after dark, but this increase was not statistically significant. In Expt 2, the short-day gilts had fewer LH pulses $(2.6 \pm 0.25$ vs. $4.6 \pm 0.24 ; P<0.01)$ in the 12-h sampling period than the long-day gilts, but the amplitude of the pulses ( $2 \cdot 28 \pm 0 \cdot 23 \mathrm{vs}$. $1 \cdot 26 \pm 0.16 \mathrm{ng} / \mathrm{ml} ; P<0.01)$ and the area under the $\mathrm{LH}$ curve $(78.8 \pm 5.60 \mathrm{vs}$. $47 \cdot 3 \pm 6 \cdot 16 ; P<0 \cdot 01)$ was greater in the short-day gilts. In the short-day, but not in the long-day, gilts LH pulses were more frequent $(2.0 \pm 0.0$ vs. $0.6 \pm 0.25 ; P<0.01)$, but had a smaller area $(61.9 \pm 7.2$ vs. $120.2 \pm 23.6 ; P<0.05)$ in the $6 \mathrm{~h}$ of dark than in the $6 \mathrm{~h}$ of light, which together made up the 12-h sampling period. These data show that, in pigs, as in other species, the concentration of melatonin in plasma increases in the dark and the duration of the nocturnal increase depends on photoperiod. The implants provided high and variable concentrations of plasma melatonin, above which a nocturnal increase was not observed. The patterns of LH secretion were consistent with the shortday gilts being closer to puberty than the long-day gilts as a consequence of differing rates of sexual maturation due to the light regimens imposed during rearing. 


\section{Introduction}

In field studies in which potential confounding factors were strictly controlled, we have shown that attainment of puberty in domestic gilts is inhibited during the summer months and that this inhibition is associated with long days (Paterson et al., 1989a, b; Paterson et al., 1991). Using controlled light regimens, which closely mimicked natural photoperiods, we subsequently demonstrated that an artificial long-day regimen, applied in the winter, suppressed puberty to levels normally seen in summer, and a short-day regimen applied in the summer produced a pubertal response typical of the winter (Paterson \& Pearce, 1990). These studies were conducted at a constant thermoneutral temperature, so the data provide compelling evidence that photoperiod is the major environmental factor responsible for the delay in puberty often observed during the summer.

It is not known how this seasonal effect is mediated in domestic pigs, but, in a wide range of species in which reproductive activity is influenced by photoperiod, including sheep (Bittman \& Karsch, 1984), Djungarian hamsters (Carter \& Goldman, 1983) and tammar wallabies (McConnell \& Tyndale-Biscoe, 1985), the photoperiodic information regulating reproduction is mediated by the 24-h secretory profile of the pineal hormone melatonin. In European wild pigs, in which reproductive activity is highly seasonal, plasma concentrations of melatonin increase within $1 \mathrm{~h}$ of darkness and reach peak values 4-5 times the daytime value (Mauget et al., 1990), suggesting that this species also uses pineal melatonin to transduce photoperiodic information.

The literature on melatonin profiles in domestic pigs is sparse and the evidence for an increase in plasma concentration at night is equivocal. Kennaway et al. (1977) reported that, in the only pig they studied, the midnight concentration of melatonin was about three times that of the midday sample. McConnell \& Ellendorff (1987) reported that three of four sows housed under $12 \mathrm{~h}$ of light/day exhibited an increase in plasma melatonin at night that was of similar magnitude to, but later in the dark phase than, that in wild pigs. However, this pattern was apparently abolished when the daylength was changed to $16 \mathrm{~h}$ of light, and did not seem to be reinstated by a further change to $8 \mathrm{~h}$ of light/day. Peacock et al. (1990a) studied pregnant sows housed under natural photoperiod conditions and found that the concentrations of plasma melatonin did not differ between night and day at any of the four times of the year examined, but the mean concentration of plasma melatonin over the 24-h sampling period varied with season. In studies with gilts $\sim 6$ months old, Brandt et al. (1986) and Diekman et al. (1990), working in the same laboratory, failed to detect an increase in serum melatonin associated with the onset of the dark phase, but, when all treatment groups in the study by Diekman et al. (1990) were pooled, mean serum concentrations of melatonin were higher during the dark than the light. When immature pigs $\sim 3$ months old were killed, either during the day or the night, no evidence of a nocturnal increase in the pineal content of melatonin or in the activity of the enzymes associated with melatonin synthesis was found, although the plasma melatonin concentrations were not measured (Reiter et al., 1987).

Melatonin plays a central role in other species in which daylength controls reproductive activity, so it is perhaps surprising that no role for melatonin has been described in domestic pigs, which we have recently shown are inhibited by long days (Paterson \& Pearce, 1990). We therefore measured plasma melatonin and luteinizing hormone $(\mathrm{LH})$ in gilts raised under the same long-day and short-day light regimens with which we demonstrated these photoperiodic effects on puberty. Gilts raised under the long-day regimen and treated with melatonin implants were included to test the hypothesis that providing exogenous melatonin would restore the plasma LH pattern to that characteristic of short days, and to provide base data on the diurnal pattern of plasma melatonin concentrations achieved in implanted gilts.

\section{Materials and Methods}

\section{Animals and housing}

A controlled-environment building with two similar rooms, each containing four pens $(2.2 \times 2.4 \mathrm{~m})$ was used in this experiment at the Western Australian Department of Agriculture, Intensive Industries Research Centre, Medina. Light in both rooms was provided by eight fluorescent tubes and the average light intensity $400 \mathrm{~mm}$ above the floor 
was 270 lux. The time of lights on and lights off was controlled by separate clocks in each room. Temperature was maintained at $23^{\circ} \mathrm{C}$ in both rooms.

Two experiments, which followed a similar format, but differed slightly in detail, were conducted in the controlledenvironment rooms. In both studies, Large White $\times$ Landrace crossbred gilts were reared together from weaning under natural daylight until they were transferred to the controlled-environment rooms. Gilts were allocated according to litter of origin so that litter mates were spread equally between the rooms where they were housed in groups of 3-5/pen.

Experiment 1. A total of 24 gilts, which were included in the study of Paterson \& Pearce (1990), were transferred to the controlled-environment rooms at an overall mean age of $107 \pm 0.5$ days on 25 September $1987(n=13)$ or 23 March $1988(n=11)$. The gilts were exposed daily to boars for 35 days from $174 \pm 0.5$ days of age and were slaughtered at a commercial abattoir at $234 \pm 0.5$ days. Attainment of puberty was assessed by mounting activity of the boar during the 35 days of exposure and after that by observation of vulval and behavioural changes. All ovaries were recovered at slaughter and the presence of morphologically normal corpora lutea $(C L)$ was required to classify the gilts as postpubertal.

Experiment 2. Fourteen gilts were transferred to the controlled-environment rooms at a mean age of $60 \pm 0.5$ days on 22 September 1989. Five gilts were housed in one room and nine in the other and they remained isolated from boars throughout the study. Of the nine gilts housed in the same room, five received two implants each containing $18 \mathrm{mg}$ of melatonin (Regulin: Schering Australia) subcutaneously behind the right ear on 5 December 1989 (133 days) and again on 3 January 1990 (162 days).

\section{Light regimens}

Two treatment regimens were created in each experiment by providing different light:dark ratios in each room. In both experiments, both rooms received $12 \mathrm{~h}$ light and $12 \mathrm{~h}$ dark (12L:12D) with lights on at $06: 00 \mathrm{~h}$ and off at 18:00 h during the first week the gilts occupied the rooms. In Expt 1, a long-day light regimen was provided in one room by increasing the length of the light phase by $15 \mathrm{~min} /$ week to reach $16 \mathrm{~L}: 8 \mathrm{D}$ at the end of the study (lights on at $04: 00 \mathrm{~h}$ ). In the other room, a short-day light regimen was provided by decreasing the length of the light phase by $15 \mathrm{~min} /$ week down to $8 \mathrm{~L}: 16 \mathrm{D}$ (lights on at $08: 00 \mathrm{~h}$ ). The lights were adjusted by $15 \mathrm{~min}$ every Friday during the study; the time of the lights being turned on changed one week and the time of lights being turned off changed the next.

In Expt 2, the light regimens, which were the same as those previously described by Paterson \& Pearce (1990), approximated more closely the naturally occurring light:dark pattern seen between the equinoxes at this latitude ( $31^{\prime \prime} 58^{\prime} \mathrm{S}$ ). Briefly, in the long-day regimen the light phase was increased by $15 \mathrm{~min} /$ week for 6 weeks then by $10 \mathrm{~min} /$ week for a further 6 weeks to give a maximum light:dark ratio of 14.5L:9.5D in the week of solstice (lights on at $04: 45 \mathrm{~h}$ ). In the short-day regimen, the light phase was decreased by $15 \mathrm{~min} /$ week for 6 weeks then by $10 \mathrm{~min} /$ week for 6 more weeks so that the light:dark ratio in the week of the solstice was 9.5L:14.5D (lights on at 07:15 h). The daylength was then increased (short-day) or decreased (long-day) by $10 \mathrm{~min}$ per week until the long-day gilts received $14 \mathrm{~L}: 10 \mathrm{D}$ and the short-day gilts 10L:14D in the week when blood sampling was carried out.

\section{Blood sampling}

All blood samples were collected via indwelling cannulae (Silastic medical grade tubing, i.d. $1.57 \mathrm{~mm}$; o.d. $3.17 \mathrm{~mm}$, Dow Corning Company, Midland, MI, USA), which were surgically inserted in the right jugular vein under halothane anaesthesia $36-48 \mathrm{~h}$ before sampling commenced.

In Expt I, samples were collected every $2 \mathrm{~h}$ between 12:00 and 18:00 h the following day from some of the gilts housed in the rooms. Samples were collected (a) during the first week the gilts occupied the rooms (12L:12D with lights on at $06: 00 \mathrm{~h}$ and off at 18:00 h, seven gilts) and (b) after 16 weeks on the artificial light regimens (16L:8D with lights on at 04:00 h and off at 20:00 h, eight gilts; 8L:16D with lights on at $08: 00 \mathrm{~h}$ and off at 16:00 h, nine gilts). Different gilts were sampled in parts (a) and (b), and in part (b) all gilts sampled had reached puberty.

In Expt 2, sampling from all gilts commenced on 10 January 1990 (169 days), when the nine long-day gilts were exposed to 14L:10D with lights on at 05:00 h and off at 19:00 h and the five short-day gilts were exposed to 10L:14D with lights on at $07: 00 \mathrm{~h}$ and off at 17:00 h. Blood was sampled for tonic LH every 15 min for $12 \mathrm{~h}$ commencing $6 \mathrm{~h}$ before lights off on Day 1 and for melatonin hourly for $24 \mathrm{~h}$ commencing at the same time as the tonic $\mathrm{LH}$ samples.

\section{Hormone assays}

Luteinizing hormone. Plasma LH concentrations were determined using a double-antibody radioimmunoassay technique previously described and validated by Niswender et al. (1970). This technique uses purified porcine LH (LER-2-206, NIH, National Institute of Diabetes, Digestive and Kidney Diseases, Baltimore, MD, USA) for both iodination and standards, antiporcine LH serum GDN No. 566 (donated by G. D. Niswender, Colorado State University, Fort Collins, USA), and requires $100 \mu \mathrm{l}$ of plasma. The limit of detection for the two assays was $0.25 \mathrm{ng} / \mathrm{ml}$ and samples containing $<0.25 \mathrm{ng} / \mathrm{ml}$ were assigned this value for analysis. Pooled plasma samples $(n=6)$ containing either a high $(1.80 \pm 5.5 \%, 1.79 \pm 3.5 \% \mathrm{ng} / \mathrm{ml})$ or a low $(0.61 \pm 10.0 \%, 0.63 \pm 11.6 \% \mathrm{ng} / \mathrm{ml})$ concentration of $\mathrm{LH}$ were included as quality controls in each assay. 
Plasma melatonin. This was assayed by the direct radioimmunoassay technique of Maxwell et al. (1989). This direct assay has been validated for sheep and deer plasma by high-performance liquid chromatography and electron capture, by gas chromatography mass spectroscopy and by comparison with an extraction-based assay which uses a different antiserum (Newman et al., in press). [O-Methyl- $\left.{ }^{3} \mathrm{H}\right]$ melatonin $(85 \mathrm{Ci} / \mathrm{mol}$ ) was purchased from the Radiochemical Centre (Amersham, UK) and antiserum (Prospect $6 \mathrm{~A}$ ) to a prepared antigen, the hemisuccinimide derivative of melatonin conjugated to human serum albumin (Foldes et al., 1983), was raised in Merino ewes in our laboratory. All other reagents were commercially available reagent grade. Standard curves and quality controls were prepared in daytime plasma collected from gilts of a similar age in the Medina herd. Each assay included quality control standards as well as recovery standards obtained by analysis of porcine plasma with known amounts of exogenous (added) melatonin. The average limit of detection (two standard deviations below the mean of triplicate zero standards) for the $1 \mathrm{I}$ assays in which samples from these experiments and the experiments described by Paterson et al. (1992) were assayed was $3.6 \mathrm{pg} / \mathrm{ml}$. The coefficient of variation of porcine samples was $10 \%$ at $80 \mathrm{pg} / \mathrm{ml}$ between assays and $13 \%$ within assays.

\section{Statistical analysis}

The serial samples were analysed for LH pulses using a version of the algorithm Pulsar developed by Merriam \& Wachter (1982), developed for the Apple Macintosh Microcomputer (Munro 1.1, Elsevier-Biosoft, Cambridge, UK) and described in detail by Martin el al. (1987). The $G$-parameters (the number of standard deviations by which a peak must exceed the baseline in order to be accepted) were $6 \cdot 0,4 \cdot 0,3 \cdot 5,2 \cdot 9$ and $2 \cdot 5$ for $G_{1}-G_{5}$, these being the requirements for pulses composed of 1-5 samples which exceed the baseline, respectively. The Baxter parameters describing the parabolic relationship between the concentration of a hormone in a sample and the standard deviation (assay variation) about that concentration were $0.04400\left(b_{1}\right.$, the $y$-intercept $), 0.00246\left(b_{2}\right.$, the $x$-coefficient $)$ and $0.01509\left(b_{3}\right.$, the $x^{2}$-coefficient). To test for the effects of treatment on LH secretion, a repeated measures analysis of variance was used, with photoperiod as the main effect. The 12-h sampling period was divided into two 6-h blocks, representing samples taken during the light and during the dark and used as the repeated measure so that interactions between photoperiod and diurnal variation could be tested. The data for LH pulse amplitude and area, and interpulse interval were not normally distributed (variance proportional to mean), so they were transformed logarithmically before analysis. The melatonin data were transformed logarithmically because the variance was proportional to the mean, and then subjected to repeated measures analysis of variance, with photoperiodic treatment as the main effect and sampling time as the repeated measure. When this revealed significant effects of sampling time or the interaction between sampling time and treatment, least significant differences $(P<0.05)$ were used to compare the values for samples during the dark periods with the basal concentration during the light periods, calculated as the mean of all samples collected when the animals in the treatment had been exposed continuously to at least $1 \mathrm{~h}$ of light.

\section{Results}

In Expt 1, analysis of variance revealed significant effects of treatment $(P=0.028)$, sampling time $(P<0.0001)$ and the interaction between treatment and sampling time $(P<0.0001)$. Mean plasma melatonin concentrations in the samples before dark were below the level of sensitivity of the assay $(3.6 \mathrm{pg} / \mathrm{ml})$ in the gilts on all three light regimens (Fig. 1). In gilts housed under all three light regimens, mean plasma melatonin concentration in the first sample taken after dark was significantly higher than that in the light phase, and it remained significantly higher for at least $8 \mathrm{~h}$. In the $12 \mathrm{~L}: 12 \mathrm{D}$ and the $8 \mathrm{~L}: 16 \mathrm{D}$ gilts, mean plasma melatonin concentrations returned to basal values in the sample coincident with the end of the dark phase and in the $16 \mathrm{~L}: 8 \mathrm{D}$ gilts basal values were measured in the first sample taken after the lights came on.

In Expt 2, analysis of variance revealed significant effects of treatment $(P<0.0001)$, sampling time $(P<0.0001)$ and the interaction between treatment and sampling time $(P<0.0001)$. Mean plasma melatonin concentrations were below the sensitivity of the assay in the $6 \mathrm{~h}$ before dark in the long-day and the short-day gilts (Fig. 2). In both treatments, mean plasma melatonin concentration was significantly greater than in the light phase in the first sample taken after dark. In the long-day gilts, plasma melatonin concentrations remained significantly higher throughout the dark phase, returning to basal values in the sample coincident with the end of the dark phase. In the short-day gilts, the release of melatonin appeared to be biphasic. Plasma melatonin was significantly greater in the first two samples after dark, then returned to basal concentrations in the next four samples before being significantly higher again in the samples taken 7, 9 and $11 \mathrm{~h}$ after the lights were turned off. In contrast, the long-day gilts implanted with melatonin had a mean plasma 

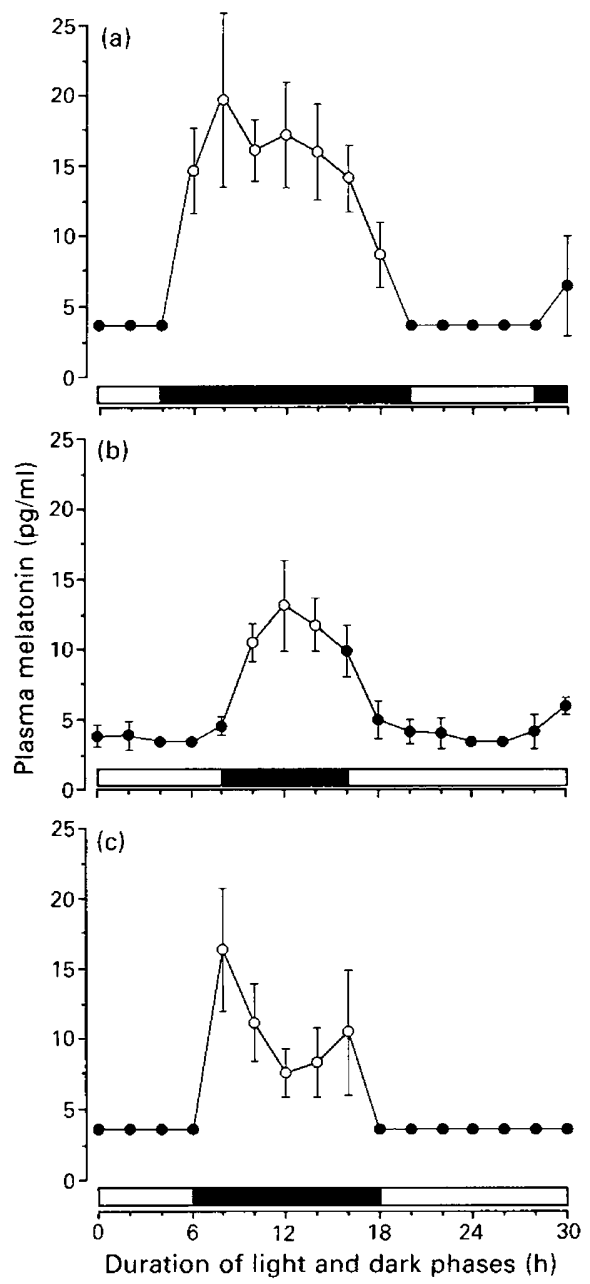

Fig. 1. Plasma melatonin concentrations (mean \pm s.e.m.) in all gilts housed under (a) short $(n=9)$; (b) long $(n=8)$; or (c) equinoctial $(n=7)$ photoperiods. Values $(O)$ measured during the dark phase $(\square)$ that were significantly $(P<0.05)$ greater than the mean basal value measured during the light phase ( $\square$ ).

melatonin concentration of $91.9 \pm 5.26 \mathrm{pg} / \mathrm{ml}$ during the light phase (Fig. 2). Plasma melatonin concentration was extremely variable both between and within gilts and, although the mean concentrations in the first two samples after dark exceeded $120 \mathrm{pg} / \mathrm{ml}$, they were not significantly different from the mean concentration during the light phase.

In all treatments, LH was secreted in clear, easily defined pulses (Fig. 3). The variables describing pulsatile secretion were analysed for the effect of photoperiodic treatment (over the whole $12 \mathrm{~h}$ ) and for differences between the light (the first $6 \mathrm{~h}$ ) and the dark (second $6 \mathrm{~h}$ ) phases. None of the $\mathrm{LH}$ variables were significantly affected by melatonin treatment in gilts on long days (Fig. 3), so the data for all long-day gilts were pooled before testing for differences between light and dark.

Analysis of variance revealed significant effects of photoperiod and light phase on LH pulse frequency and interpulse interval (Figs 3 and 4). The pulses were secreted more frequently on long days than on short days ( $P<0.01$ for frequency; $P=0.05$ for interval) and more frequently during the night than during the day $(P=0.02 ; P=0.06)$. Although the interaction between the factors did not reach statistical significance, there was a significant diurnal difference in pulse frequency 

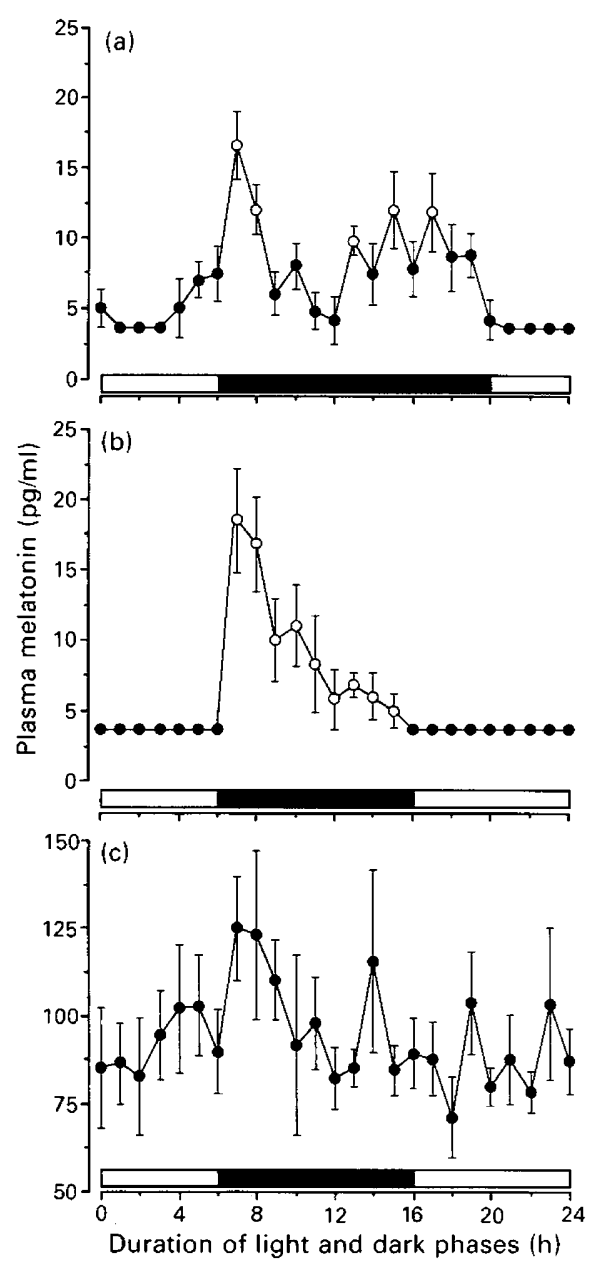

Fig. 2. Plasma melatonin concentrations (mean \pm s.e.m.) in all gilts housed under (a) short $(n=5)$ photoperiod, or long photoperiod (b) without $(n=4)$ or (c) with $(n=5)$ subcutaneous melatonin implants. Values $(\bigcirc)$ measured during the dark phase $(\mathbb{b})$ that were significantly $(P<0.05)$ greater than the mean basal value measured during the light phase $(\square)$.

$(t=5.69 ; P<0.01)$ in the short-day gilts. Pulse amplitude and pulse area were also affected by photoperiod and light phase, with smaller pulses observed on long-day than on short-day ( $P=0.034$ for amplitude; $P=0.05$ for area). There was a tendency for the effect of light phase to be greater on short days than on long days and this interaction was statistically significant for pulse area $(P=0.05)$. However, we interpreted this result with caution because of the highly variable nature of pulse amplitude and the low pulse frequency observed in the light phase. Interpulse nadir and mean concentrations of LH were not affected by either factor (Fig. 4).

\section{Discussion}

Plasma melatonin concentration increased after the onset of darkness in postpubertal and prepubertal gilts on long-day and short-day regimens and in immature gilts on an equinoctial regimen. These data clearly demonstrate the existence of a nocturnal increase of plasma melatonin in domestic gilts under a wide range of conditions. The pattern of plasma melatonin in the dark phase, 


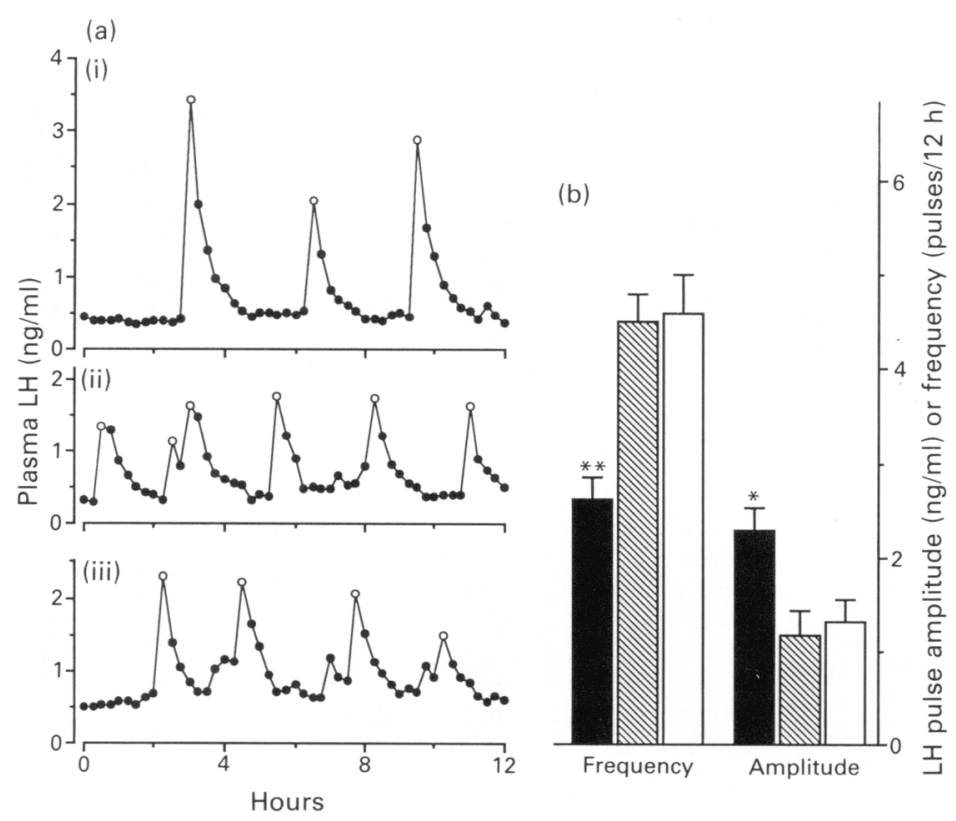

Fig. 3. Effect of photoperiod and melatonin on the secretion of luteinizing hormone (LH) in gilts. (a) Representative profiles from gilts on (i) short days; (ii) long days; or (iii) long days plus melatonin; the peaks of significant pulses are indicated $(O)$; (b) frequency and amplitude of pulses (mean \pm s.e.m.; ${ }^{*} P<0.05 ;{ }^{* *} P<0.01$ ) in gilts on $(\boldsymbol{\square})$ short days, $(\mathbb{\mathbb { N }})$ long days, or $(\square)$ long days plus melatonin.

with peak concentrations measured $1-2 \mathrm{~h}$ after lights off followed by a gradual decline towards baseline, is almost identical to that reported for European wild pigs (Mauget et al., 1990). Reproductive activity in this species exhibits a high degree of seasonality, which is controlled by photoperiod (Mauget, 1982) and, as in other species, the diurnal variation in melatonin is believed to be the means by which photoperiodic information is transduced. The recent finding that photoperiod is the major environmental factor controlling attainment of puberty in domestic gilts (Paterson \& Pearce, 1990) and the marked similarity in the melatonin pattern to that of the European wild boar observed in this study suggests that this physiological mechanism can be extended to domestic pigs.

Our observation of a nocturnal increase of plasma melatonin in the majority of gilts of differing ages housed under a range of photoperiod regimens is contrary to reports that plasma melatonin is either not increased in the dark (Brandt et al., 1986; Reiter et al., 1987; Peacock et al., 1990a) or, if there is an increase, it is only present under certain conditions (McConnell \& Ellendorff, 1987) or can only be measured as mean day versus night concentrations in pooled data (Diekman et al., 1990). In probably the most detailed study on this topic published to date, McConnell and Ellendorff (1987) observed a nocturnal increase in three of four sows housed at $12 \mathrm{~h}$ light/day, but the concentrations of melatonin they measured were much higher and the peak occurred much later in the dark phase than in our gilts. The higher concentrations of plasma melatonin may be due to differences in the assay methodology, or the maturity or breed of the animals used, but there is no obvious explanation for the delay of $5 \mathrm{~h}$ before peak concentrations were measured. In all the gilts in our study that had a nocturnal increase of plasma melatonin, the peak concentrations were measured in the first or second sample after the lights were turned off. This is similar to the pattern of plasma melatonin reported in other species (Lincoln et al., 1982; Arendt, 1986) suggesting that this is the normal response to the onset of darkness in animals that use plasma melatonin to monitor daylength. We also disagree with the conclusion of McConnell \& Ellendorff 

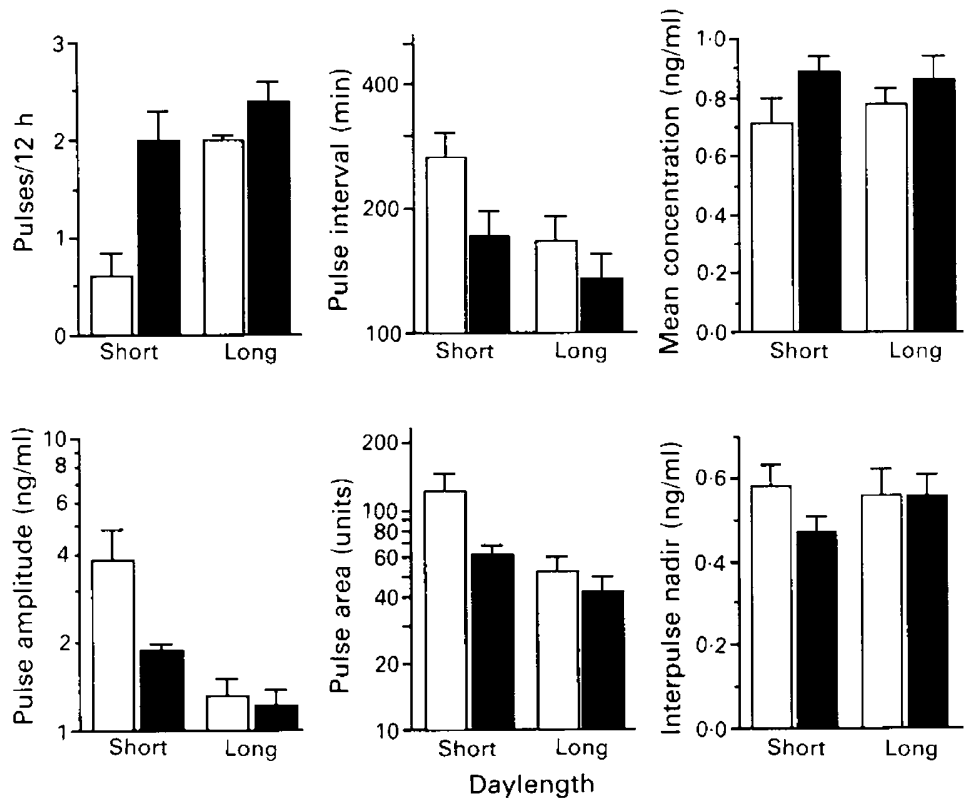

Fig. 4. Six characteristics of the secretion of luteinizing hormone (LH) during the light $(\square)$ and dark phase $(\boldsymbol{Q})$ in gilts reared under either a short-day $(n=5)$ or a long-day $(n=9)$ regimen. The data for the animals on long days were pooled from those with $(n=5)$ and without $(n=4)$ melatonin implants when analysis revealed no significant effect of melatonin on any of the variables describing $\mathrm{LH}$ secretion.

(1987) that pigs only have a nocturnal increase in plasma melatonin when housed on an equinoctial light regimen. Our data show this is clearly not the case, because nocturnal increases of plasma melatonin were observed in long-day and short-day gilts in both experiments. The reason for this discrepancy between the two studies is unknown, but it may lie in the photoperiod protocols: we used stepwise changes in photoperiod in our studies to mimic the rate of change to which pigs are normally exposed, whereas McConnell \& Ellendorff (1987) changed the daylength in single 4-h or 8-h steps. Domestic pigs might not be able to interpret such large changes in daylength and their ability to monitor daylength via a nocturnal increase in plasma melatonin may be impaired even after a long period of exposure to the new light regimen.

Brandt et al. (1986), Diekman et al. (1990) and Peacock et al. (1990a) all failed to observe nocturnal increases of plasma melatonin, despite using appropriate sampling protocols and pigs of comparable age and breed to those in the present study. Unfortunately, all three studies were published only as abstracts and we cannot compare details of the melatonin assays used. Under certain conditions, radioimmunoassays are not sufficiently sensitive or specific to detect changes such as those we have reported here because they overestimate basal concentrations. Such problems have been encountered with the measurement of melatonin in human plasma (Turek \& van Cauter, 1988). This may explain the disagreements among the data for domestic pigs, because the daytime melatonin concentrations measured in the studies in which no nocturnal increase of melatonin was detected were up to 100 times higher than those measured in the present study.

Our data show that immature pigs $\sim 100$ days old have already established a diurnal rhythm of plasma melatonin. The only other data available on pigs of this age are those of Reiter et al. (1987), who measured enzyme activity in, and melatonin content of, the pineal glands of 3-month-old pigs slaughtered during the day or the night. They found no evidence of a nocturnal increase in the activity of enzymes involved in melatonin synthesis; but pineal melatonin was lower in the pigs 
killed at night, an observation compatible with the concept that melatonin had been released from the pineal early in the dark phase, which started some hours before the pigs were killed.

Plasma LH was released in a pulsatile manner in all treatment groups in Expt 2, but the characteristics of this pulsatile secretion differed between treatments, short-day gilts having less frequent, but larger LH pulses. Cox et al. (1987) reported that mean basal LH and mean pulse amplitude were greater in ovariectomized sows in the summer than at other times of the year, but they found no difference in the frequency of pulses. Similarly, Peacock et al. (1990b) reported that ovariectomized sows with oestradiol implants had higher basal LH and larger, but not more frequent, pulses when housed at $16 \mathrm{~L}: 8 \mathrm{D}$ than at $8 \mathrm{~L}: 16 \mathrm{D}$. These data differ somewhat from ours, but their direct comparison with those for the present study is difficult because we used intact gilts. However, Peacock et al. (1990b) also reported a higher basal LH concentration with a trend for morefrequent, larger pulses in summer than at other times of the year in pregnant sows. These data are also somewhat different to ours; pulses were more frequent in our long-day gilts, but their basal LH concentration was not higher and the mean pulse amplitude was greater in short-day gilts. These differences may be accounted for by the different physiological and maturational state of the animals in the two studies because the frequency $(>1 / \mathrm{h})$ and baseline $(2.24 \mathrm{ng} / \mathrm{ml})$ of the pregnant sows in the summer in the study of Peacock et al. (1990b) differed greatly from either the long-day or the short-day gilts in our experiments.

The difference in LH secretion between the long-day and short-day gilts probably reflects the physiological consequence of differing rates of maturation due to the light regimen imposed. Several authors have reported that LH secretion changes during development from birth to puberty in the gilt, with an increase in the frequency of pulses and/or mean LH concentration between 70 and 135 days of age followed by a decrease thereafter in the period leading up to puberty (Wise et al., 1981; Diekman et al., 1983; Camous et al., 1985). A similar period of high transient LH secretion has been reported in rats (Döhler \& Wuttke, 1975), sheep (Foster et al., 1975) and cattle (Lacroix \& Pelletier, 1979). Camous et al. (1985), suggested that this decline in LH secretion in pigs was a response to the development of ovarian activity and negative feedback and, as such, indicated increasing maturity. Indeed, it appears that the earlier the depression of LH takes place, the earlier puberty is attained. This concept is consistent with the difference in LH secretion between long-day and short-day gilts. Based on previous studies using the same light regimens (Paterson \& Pearce, 1990), attainment of puberty in gilts reared on the long-day regimen would be inhibited compared with those on the short-day regimen, i.e. at 165 days of age the short-day gilts were closer to puberty and more mature than the long-day gilts. Pulses of LH in the short-day gilts were less frequent at this age, suggesting that negative feedback had already started to operate whereas in the long-day gilts the suppression of LH secretion had not yet begun. A further point indicating that the short-day gilts were more physiologically mature at the same chronological age is that they showed diurnal variation in LH secretion, a phenomenon associated with the advanced prepubertal stage in humans (Boyar et al., 1976), hamsters (Smith \& Stetson, 1980) and rats (Andrews \& Ojeda, 1981).

Secretion of LH in the long-day gilts was not affected by the continuous high concentration of plasma melatonin provided by the implants, suggesting that the inhibition of development of the hypo-pituitary ovarian axis imposed by the long-day photoperiod was not overcome by the implants. This suggestion is supported by the recent observation of Paterson (1990), that melatonin implants given to gilts under shed conditions in the summer did not prevent the seasonal inhibition of puberty, which is mediated by daylength (Paterson \& Pearce, 1990). In sheep (Lincoln \& Ebling, 1985; English et al., 1986), deer (Adam et al., 1989) and goats (McGregor et al., 1989), melatonin implants can stimulate reproductive activity under inhibitory photoperiods, but this does not appear to be the case in gilts. The continuous high concentrations of plasma melatonin may have provided an inappropriate hormonal milieu that the gilts could not interpret. Alternatively, the gilts may have interpreted the melatonin signal they received as a total dark or ultrashort-day situation. Such conditions are also inhibitory to reproductive activity in pigs (Hacker et al., 1979; 
Ntunde et al., 1979; Diekman \& Grieger, 1988) and this would explain why LH secretion in the implanted gilts was characteristic of animals whose reproductive activity is inhibited.

We thank H. Payne, J. Pluske, A. Pearce, M. Blackberry and D. Urquart for technical assistance with surgery and blood sampling. Schering Australia generously donated the melatonin implants used in this study.

\section{References}

Adam, C.L., Moir, C.E. \& Shiach, P. (1989) Melatonin can induce year-round cyclicity in red deer (Cervus elaphus). J. Reprod. Fert. 87, 401-408.

Andrews, W.W. \& Ojeda, S.R. (1981) A detailed analysis of the serum luteinizing hormone secretory profile in conscious, free-moving female rats during the time of puberty. Endocrinology 109, 2023-2039.

Arendt, J. (1986) Role of the pineal gland and melatonin in seasonal reproductive function in mammals. Oxford Revien's of Reproductive Biology 8, 266-320.

Bittman, E.L. \& Karsch, F.J. (1984) Nightly duration of pineal melatonin secretion determines the reproductive response to inhibitory day length in the ewe. Biol. Reprod. 30, 585-593.

Boyar, R., Wu, R.H.K., Roffwarg, H., Kapen, S., Weitzman, E.D., Hellman, L. \& Finkelstein, J.W. ( 1976$)$ Human puberty: 24-hour estradiol patterns in pubertal girls. J. c'in. Endocr. Metab. 43, 1418-1421.

Brandt, K.E., Diekman, M.A., Green, M.L. \& Malayer, J.R. (1986) Lack of a circadian rhythm in serum concentrations of melatonin in prepubertal gilts. $J$. Anim. Sci. 63, 356 (abst).

Camous, S., Prunier, A. \& Pelletier, J. (1985) Plasma prolactin, LH, FSH and estrogen excretion patterns in gilts during sexual development. J. Anim. Sci. 60, $1308-1317$.

Carter, D.S. \& Goldman, B.D. (1983) Antigonadal effects of timed melatonin infusion in pinealectomized male Djungarian hamsters (Phodopus sungorus sungorus): duration is the critical parameter. Endocrinology 113, $1261-1267$.

Cox, N.M., Ramirez, J.L., Matamoros, I.A., Bennett, W.A. \& Britt, J.M. (1987) Influence of season of estrus and luteinizing hormone responses to estradiol benzoate in ovariectomized sows. Theriogenology 27, $395-405$.

Diekman, M.A. \& Greiger, D.M. (1988) Influence of various intensities of supplemental lighting during decreasing daylengths on puberty in gilts. Anim. Reprod. Sci. 16, 295-301.

Diekman, M.A., Trout, W.E. \& Anderson, L.L. (1983) Serum profiles of LH, FSH and prolactin from 10 weeks of age until puberty in gilts. J. Anim. Sci. 56, 139-145.

Diekman, M.A., Green, M.L. \& Hudgens, R.E. (1990) Serum concentrations of melatonin in gilts exposed to total darkness or direct sunlight. J. Reprod. Fert. Suppl. 40, 37I (abst).

Döhler, K.D. \& Wuttke, W. (1975) Changes with age in levels of serum gonadotropins, prolactin and gonadal steroids in prepubertal male and female rats. Endocrinology 97, 898-907.
English, J., Poulton, A.L., Arendt, J. \& Symons, A.M. (1986) A comparison of the efficiency of melatonin treatments in advancing oestrus in ewes. $J$. Reprod. Fert. 77, 321-327.

Foldes, A., Hoskinson, R.M., Scaramuzzi, R.J. \& Maxwell, C.A. (1983) Modification of sheep pineal $\beta$-adrenoceptors by some gonadal steroids but not by melatonin. Neuroendocrinology 37, 378-385.

Foster, D.L., Lemons, A., Jaffe, R.B. \& Niswender, G.D. (1975) Sequential patterns of circulating luteinizing hormone and follicle-stimulating hormone in female sheep from early postnatal life through the first estrous cycles. Endocrinology 97, 985-994.

Hacker, R.R., King, G.J., Ntunde, B.N. \& Narendran, R. (1979) Plasma oestrogen, progesterone and other reproductive responses of gilts to photoperiods. $J$. Reprod. Fert. 57, 447-451.

Kennaway, D.J., Firth, G., Phillipou, G., Matthews, C.D. \& Seamark, R.F. (1977) A specific radioimmunoassay for melatonin in biological tissue and fluids and its validation by gas chromatography-mass spectrometry. Endocrinology 101, 119-127.

Lacroix, A. \& Pelletier, J. (1979) Short-term variations in plasma $\mathrm{LH}$ and testosterone in bull calves from birth to one year of age. J. Reprod. Fert. 55, 81-85.

Lincoln, G.A. \& Ebling, F.J.P. (1985) Effect of constantrelease implants of melatonin on seasonal cycles in reproduction, prolactin secretion and moulting in rams. J. Reprod. Fert. 73, 241-253.

Lincoln, G.A., Almeida, O.F.X., Klandorf, H. \& Cunningham, R.A. (1982) Hourly fluctuations in the blood levels of melatonin, prolactin, luteinizing hormone, testosterone, tri-iodothyronine, thyroxine and cortisol in rams under artificial photoperiods and the effects of cranial sympathectomy. J. Endocr. 92, $237-250$.

Martin, G.B., Taylor, P.L. \& McNeilly, A.S. (1987) Effect of small doses of bovine follicular fluid on the tonic secretion of gonadotrophins in the ewe. $J$. Endocr. 114, 73-79.

Mauget, R. (1982) Seasonality of reproduction in the wild boar. In Control of Pig Reproduction, pp. 509-526. Eds D. J. A. Cole \& G. R. Foxcroft. Butterworths, London.

Mauget, R., Ravault, J.P., Chesneau, D., Locatelli, A., Saboureau, M., Sempere, A.J. \& Lacroix, A. (1990) Peripheral plasma melatonin concentrations in the European wild boar: circadian and seasonal variations. J. Reprod. Fert. Suppl. 40, 371 (abst).

Maxwell, C.A., Rintoul, A.J., Foldes, A., Downing, J.A., Scaramuzzi, R.J. \& Carter, N.B. (1989) Seasonal modification of ovine pineal function. 2. Steroidal effects on 
melatonin and prolactin profiles. Neuroendocrinology 50, 274-279.

McConnell, S.J. \& Ellendorff, F. (1987) Absence of nocturnal melatonin surge under long and short artificial photoperiods in the domestic sow. J. Pineal Res. 4, 20I-210 and Erratum 4, 341-348.

McConnell, S.J. \& Tyndale-Biscoe, C.H. (1985) Response in peripheral plasma melatonin to photoperiod change and the effects of exogenous melatonin on seasonal quiescence in the tammar Macropus eugenii. J. Reprod. Fert. 73, 529-538.

McGregor, B.A., McPhee, S.R., Williams, A.W., Earle, C.R. \& Stapels, L.D. (1989) Melatonin treatment improves kidding percentage in angora does. Proc. Aust. Soc. Reprod. Biol. 21, 98 (abst).

Merriam, G.R. \& Wachter, K.W. (1982) Algorithms for the study of episodic hormone secretion. Am. J. Physiol. 243 (Endocr. Metab. 6), E310-E318.

Newman, R.E., Foldes, A., Maxwell, C.A., Rigby, R.D.G. \& Wynn, P.C. (in press) Identification of a seasonal elevation in daytime melatonin levels associated with the rut in fallow bucks (Dama dama): the effect of daylength and exogenous melatonin. J. Pineal Res.

Niswender, G.D., Reichert, L.E. \& Zimmerman, D.R. (1970) Radioimmunoassay of serum levels of luteinizing hormone throughout the estrous cycle in pigs. Endocrinology 87, 576-580.

Ntunde, B.N., Hacker, R.R. \& King, G.J. (1979) Influence of photoperiod on growth, puberty and plasma LH levels in gilts. J. Anim. Sci. 48, 1401-1406.

Paterson, A.M. (1990) Seasonal inhibition of puberty in domestic gilts is not prevented by melatonin implants. Proc. Aust. Soc. Reprod. Biol. 22, 22 (abst).

Paterson, A.M. \& Pearce, G.P. (1990) Attainment of puberty in domestic gilts reared under long-day or short-day artificial light regimens. Anim. Reprod. Sci. 23, 135-144

Paterson, A.M., Hughes, P.E. \& Pearce, G.P. (1989a) The effect of limiting the number of days of contact with boars, season and herd of origin on attainment of puberty in gilts. Anim. Reprod. Sci. 18, 293-30I.

Paterson, A.M., Hughes, P.E. \& Pearce, G.P. (1989b) The effect of season, frequency and duration of contact with boars on the attainment of puberty in gilts. Anim. Reprod. Sci. 21, 115-124.

Paterson, A.M., Pearce, G.P. \& D'Antuono, M.F. (1991) Seasonal variation in attainment of puberty in isolated and boar-exposed domestic gilts. Anim. Reprod. Sci. 24, 323-333.

Paterson, A.M., Maxwell, C.A. \& Foldes, A. (1992) Seasonal inhibition of puberty in domestic gilts is overcome by melatonin administered orally, but not by implant. J. Reprod. Fert. 94, 97-105.

Peacock, A.J., Love, R.J. \& Evans, G. (1990a) Plasma melatonin levels in sows are lowest during winter. $J$. Reprod. Fert. Suppl. 40, 37 I (abst).

Peacock, A.J., Love, R.J. \& Evans, G. (1990b) Photoperiodic involvement in elevated LH concentrations in sows during summer. J. Reprod. Fert. Suppl. 40, 371 (abst).

Reiter, R.J., Britt, J.M. \& Armstrong, J.D. (1987) Absence of a nocturnal rise in either norepinephrine, $\mathrm{N}$ acetyltransferase, hydroxyindole- $O$-methyltransferase or melatonin in the pineal gland of the domestic pig kept under natural environmental photoperiods. Neurosci. Lett. 81, 171-176.

Smith, S.G. \& Stetson, M.H. (1980) Maturation of the clock-timed gonadotropin release in hamsters. Endocrinology 107, 1334-1337.

Turek, F.W. \& Van Cauter, E. (1988) Rhythms in reproduction. In The Physiology of Reproduction, pp. 1789-1830. Eds E. Knobil \& J. Neill. Raven Press, New York.

Wise, M.E., Faltys, G.L. \& Zimmerman, D.R. (1981) Luteinizing hormone secretion from birth to puberty in the gilt. J. Anim. Sci. 53, 377 (abst).

Received 19 September 1990 